\title{
Current experimental strategies for intracellular target identification of microRNA
}

\author{
Jinbo Li@ and Yan Zhang*
}

\begin{abstract}
Intracellular target identification of microRNA (miRNA), which is essential for understanding miRNA-involved cellular processes, is currently the most challenging task in miRNA-related studies. Although bioinformatic methods have been developed as the most efficient strategy for miRNA target identification, high-throughput experimental strategies are still highly demanded. In this review paper, we summarize and compare current experimental strategies for miRNA target identification, including gene expression profiling, immunoprecipitation and pull-down methods. Gene expression profiling methods mainly rely on the measurement of target gene expression through overexpression or inhibition of specific miRNA, which are indirect strategies to unveil miRNA targets. Immunoprecipitation methods use specific antibody to isolate RISC and bound mRNAs, followed by analysis with high-throughput techniques and bioinformatics to reveal miRNA-mRNA interactions. Pull-down methods use tagged miRNA mimics as probes to isolate associated target genes through affinity purification, which directly indicate miRNA-mRNA interactions after analysis of isolated target genes. Each method has its own advantages and limitations, which will be summarized and discussed in details. Overall, this review paper aims to provide a brief outline of recent achievements at experimental strategies for miRNA target identification. With the further development or improvement, we envision these experimental strategies will ultimately contribute a lot to the research on miRNA and miRNA-targeted biomedicine.
\end{abstract}

Keywords: microRNA, Target identification, Experimental strategies

\section{Introduction}

MicroRNAs (miRNAs) are endogenous small-noncoding RNAs with the length of $\sim 22$ nucleotides, which can regulate gene expression at the post-transcriptional level [1]. Since the first discovery of lin-4 $[2,3]$ and let-7 $[4,5]$ in C.elegans, more than 2500 miRNAs have been found and identified in human beings [6]. Meanwhile, a single miRNA could target multiple genes and over one third of human genes were predicted as conserved miRNA targets [7], suggesting miRNAs participate in almost all cellular processes through regulating their target genes. Recent evidences also revealed miRNAs were involved in not only normal physiological processes but also pathologies $[8,9]$. The abnormal expression or function of miRNAs were closely related with diverse human diseases, such as cancers. MiRNAs are thus

\footnotetext{
* Correspondence: njuzy@nju.edu.cn

State Key Laboratory of Analytical Chemistry for Life Sciences, School of Chemistry and Chemical Engineering, Nanjing University, Nanjing 210023, China
}

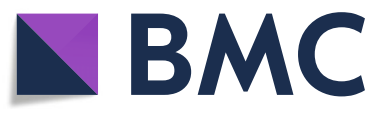

(c) The Author(s). 2019 Open Access This article is distributed under the terms of the Creative Commons Attribution 4.0 International License (http://creativecommons.org/licenses/by/4.0/), which permits unrestricted use, distribution, and reproduction in any medium, provided you give appropriate credit to the original author(s) and the source, provide a link to the Creative Commons license, and indicate if changes were made. The Creative Commons Public Domain Dedication waiver (http://creativecommons.org/publicdomain/zero/1.0/) applies to the data made available in this article, unless otherwise stated. emerging as novel endogenous bio-targets for diagnostics and therapeutic treatments [10, 11]. Understanding miRNA-involved cellular processes, including a clear picture of regulatory networks of intracellular miRNAs, is therefore essential and critical for miRNA-targeted biomedicine [12, 13], which still represents a big challenge in miRNA-related investigations. It is worth noting that phase I clinical trials of miR-34 in cancer treatment were recently terminated due to severe immune-reactions with unknown reasons [10], which is mainly due to the lack of information about miR-34 regulatory networks and further highlights the importance of miRNA target identification before proceeding to therapeutics.

The basic mechanisms of miRNA action and function on regulating their target genes have been elucidated in considerable details [14]. Generally, mature miRNAs are first incorporated into RNA-induced silencing complexes (RISC) with Argonaute (AGO) as the key proteins that bind miRNAs, followed by binding of miRNAs with the 
3'-untranslated region (3'-UTR) of target mRNAs through sequence complementarity to induce mRNA degradation or translational repression (Fig. 1). Bases 2-8 of miRNAs at the 5 -end are thought to be conserved among miRNA families and key positions that determine the binding of miRNAs with 3'-UTR of target mRNAs, which are usually known as the "seed regions" of miRNAs [12]. Sites in the 3'-UTR of target mRNAs that are complementary to miRNAs are usually known as "canonical" binding sites. According to these information, bioinformatic methods based on different algorithms have been developed to predict miRNA target genes [15-17], which is also the most commonly used strategy for exploring miRNA targets now. However, bioinformatic methods may give false positive results and additional experiments are always needed to validate prediction results [18]. Moreover, recent studies also revealed that "non-canonical" binding sites exist for some miRNAs to regulate their target mRNAs [19-21] and miRNAs could also interact with non-coding RNAs [22], which cannot be predicted by bioinformatic methods either. How to fully identify targets that can interact with specific miRNA and subsequently understand miRNA function on regulation of these targets still are the most challenging tasks in miRNA studies, which require practical experimental strategies to identify their intracellular targets.

Current experimental strategies for isolation and identification of miRNA targets mainly rely on three methods (Fig. 1) $[23,24]$. (1) Gene expression profiling methods, which indirectly indicate miRNA targets through measuring gene expression changes after overexpression or inhibition of specific miRNA. (2) Immunoprecipitation methods, which isolate RISC using specific antibody to capture miRNA targets in RISC for further analysis. (3) Pull-down methods, which use chemical tags-labeled miRNA mimics as probes to enrich miRNA-associated target genes through affinity purification for further analysis. In this review paper, we introduce the general principles and applications of current experimental strategies for miRNA target identification. Comparison and discussion on the advantages and limitations of these strategies will also be presented.

\section{Experimental strategies for miRNA target identification}

Measuring global gene expression changes post modulation in miRNA expression represents an indirect strategy for miRNA target identification. In order to realize direct target identification, efficient isolation of miRNA targets is necessary. Isolation methods based on immunoprecipitation of RISC with specific antibody and pull-down of miRNAmRNA complexes with different chemical tags have been developed. In combination with bioinformatics and high-throughput techniques such as microarray and RNA sequencing (RNA-seq), high-throughput analysis of these isolated targets could be performed to reveal miRNAmRNA interactions. In this section, we introduce the principles and applications of different experimental strategies for miRNA target identification. Summarization and comparison of different experimental strategies were listed in Table 1.

\section{Gene expression profiling}

miRNAs function by regulating target gene expression through mediating mRNA degradation or inhibition of mRNA translation [1], indicating miRNA targets could be indirectly found out by quantifying expression changes of target genes including mRNAs and proteins

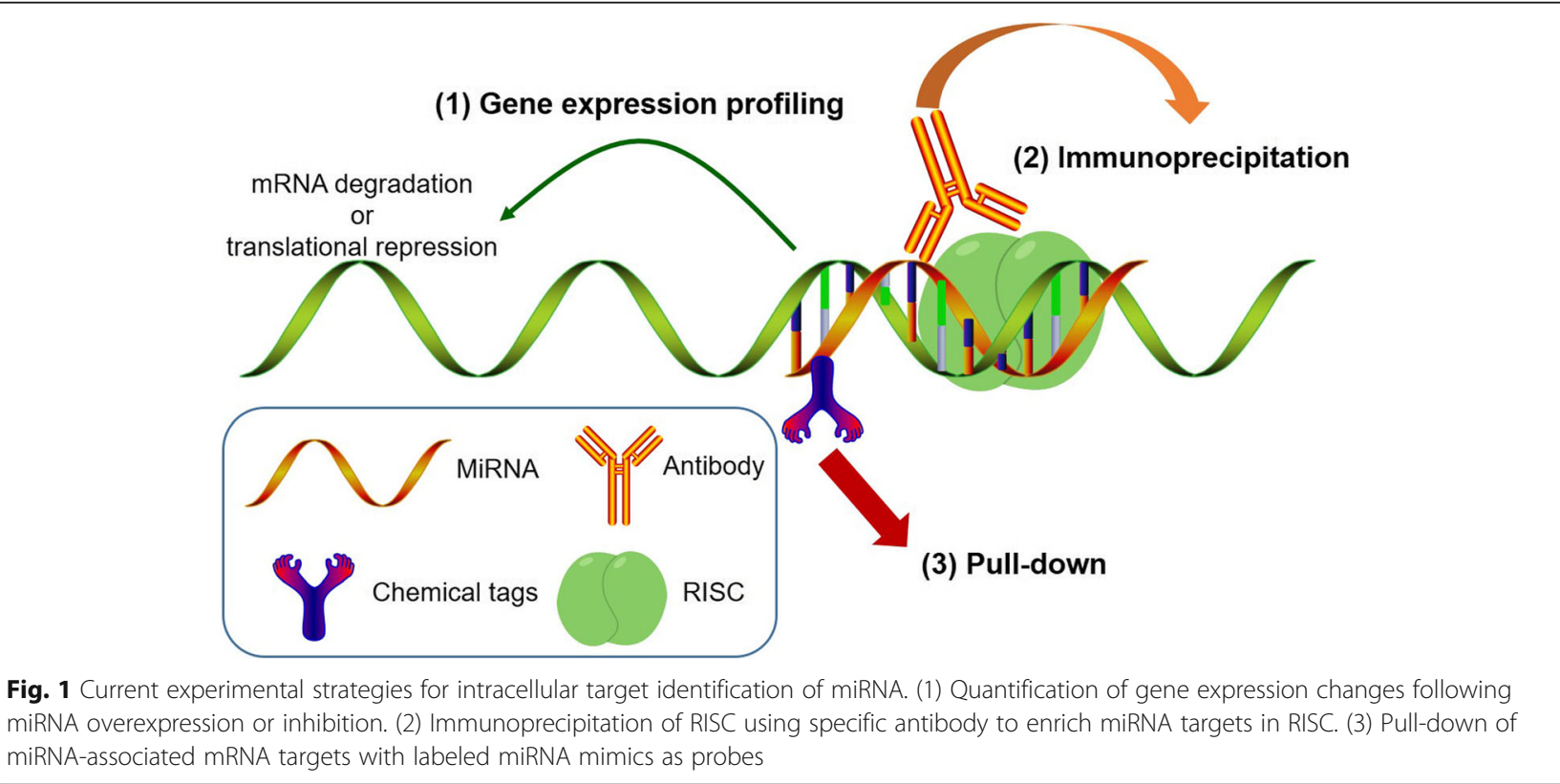


Table 1 Summarization and comparison of current experimental strategies for intracellular target identification of miRNAs

\begin{tabular}{|c|c|c|c|}
\hline \multicolumn{2}{|l|}{ Experimental strategies and references } & \multirow[b]{2}{*}{$\begin{array}{l}\text { Advantages } \\
\text {-A straightforward method to } \\
\text { identify direct targets for miRNAs } \\
\text { - High sensitivity } \\
\text { •Easy to adopt }\end{array}$} & \multirow{2}{*}{$\begin{array}{l}\text { Limitations } \\
\text {-High costs } \\
\text {-Lack of 3'-UTR libraries } \\
\text {-Low throughput } \\
\text {-Unable to identify non-canonical } \\
\text { targets }\end{array}$} \\
\hline $\begin{array}{l}\text { Gene expression profiling through } \\
\text { overexpression or inhibition of } \\
\text { specific miRNA }\end{array}$ & $\begin{array}{l}\text { Luciferase reporter screening } \\
\text { systems }[25,26]\end{array}$ & & \\
\hline & Microarray analysis $[27,28]$ & $\begin{array}{l}\text {-Simultaneous identification of } \\
\text { a subset of genes }\end{array}$ & \multirow{3}{*}{$\begin{array}{l}\text { - Difficult to distinguish direct and } \\
\text { indirect miRNA targets } \\
\text { - No information about miRNA-mRNA } \\
\text { interaction } \\
\text {-High false-positive and false-negative } \\
\text { results }\end{array}$} \\
\hline & $\begin{array}{l}\text { Stable isotope labeling by } \\
\text { amino acids in cell culture } \\
\text { (SILAC) }[29,30]\end{array}$ & $\begin{array}{l}\text {-Easy quantification of protein } \\
\text { production through metabolic } \\
\text { labeling }\end{array}$ & \\
\hline & Ribosome profiling [31] & -Measuring mRNA translation & \\
\hline \multirow[t]{3}{*}{$\begin{array}{l}\text { Immunoprecipitation of RISC } \\
\text { with specific antibody }\end{array}$} & Immunoprecipitation (IP) $[32,35]$ & $\begin{array}{l}\text {-Avoid false-positive targets } \\
\text { outside RISC }\end{array}$ & \multirow{2}{*}{$\begin{array}{l}\text { - Limited by the specificity of } \\
\text { antibody } \\
\text { - Low efficiency } \\
\text {-Non-specific to miRNA }\end{array}$} \\
\hline & $\begin{array}{l}\text { Crosslinking and immunoprecipitation } \\
\text { (CLIP) }[36,37]\end{array}$ & $\begin{array}{l}\text {-Increase in capture efficiency } \\
\text { due to photo-crosslinking }\end{array}$ & \\
\hline & $\begin{array}{l}\text { Crosslinking, immunoprecipitation } \\
\text { and sequencing of hybrids } \\
\text { (CLASH) }[19,40]\end{array}$ & $\begin{array}{l}\text {-Clear information about miRNA- } \\
\text { mRNA interaction due to ligation } \\
\text { of miRNA-mRNA in RISC }\end{array}$ & $\begin{array}{l}\text { - Limited by the specificity of antibody } \\
\text { and crosslinking efficiency } \\
\text { - Low efficiency }\end{array}$ \\
\hline \multirow[t]{3}{*}{$\begin{array}{l}\text { Pull-down with labeled } \\
\text { miRNA mimics }\end{array}$} & $\begin{array}{l}\text { 3'-biotinylated miRNA probes } \\
\text { [41-43] }\end{array}$ & $\begin{array}{l}\text {-High efficiency } \\
\text {-Specific to miRNA }\end{array}$ & $\begin{array}{l}\text {-Side effect of 3'-biotinylation on } \\
\text { miRNA function }\end{array}$ \\
\hline & $\begin{array}{l}\text { MiRNA crosslinking and } \\
\text { immunoprecipitation } \\
\text { (miR-CLIP) [22] }\end{array}$ & $\begin{array}{l}\text {-Avoid side effect of biotinylation } \\
\text { on miRNA function } \\
\text {-Specific to miRNA }\end{array}$ & $\begin{array}{l}\text { - Limited by the specificity of antibody } \\
\text { and crosslinking efficiency } \\
\text {-Low efficiency } \\
\text { - Not universal for other miRNAs }\end{array}$ \\
\hline & Photo-clickable miRNA [47] & $\begin{array}{l}\text {-A universal strategy for } \\
\text { different miRNAs } \\
\text {-Specific to miRNA }\end{array}$ & $\begin{array}{l}\text {-Possible dissociation between } \\
\text { photo-clickable miRNA and target } \\
\text { mRNAs during pull-down }\end{array}$ \\
\hline
\end{tabular}

post overexpression or suppression of specific miRNA (Fig. 2). Using this method, gene expression profiling strategies based on luciferase reporter screening systems and high-throughput quantification of global gene expression have been developed to identify miRNA targets (Table 1).

Since miRNAs regulate gene expression through interaction with the 3'-UTR of target mRNAs, screening possible miRNA targets using cellular reporter systems bearing 3'-UTR of different mRNAs is also a straightforward way to identify miRNA targets. The reporter systems were constructed by transfection of luciferase reporter genes containing 3'-UTR of human genes into cells, followed by introducing miRNA of interest into these cells to modulate luciferase expression (Fig. 2).

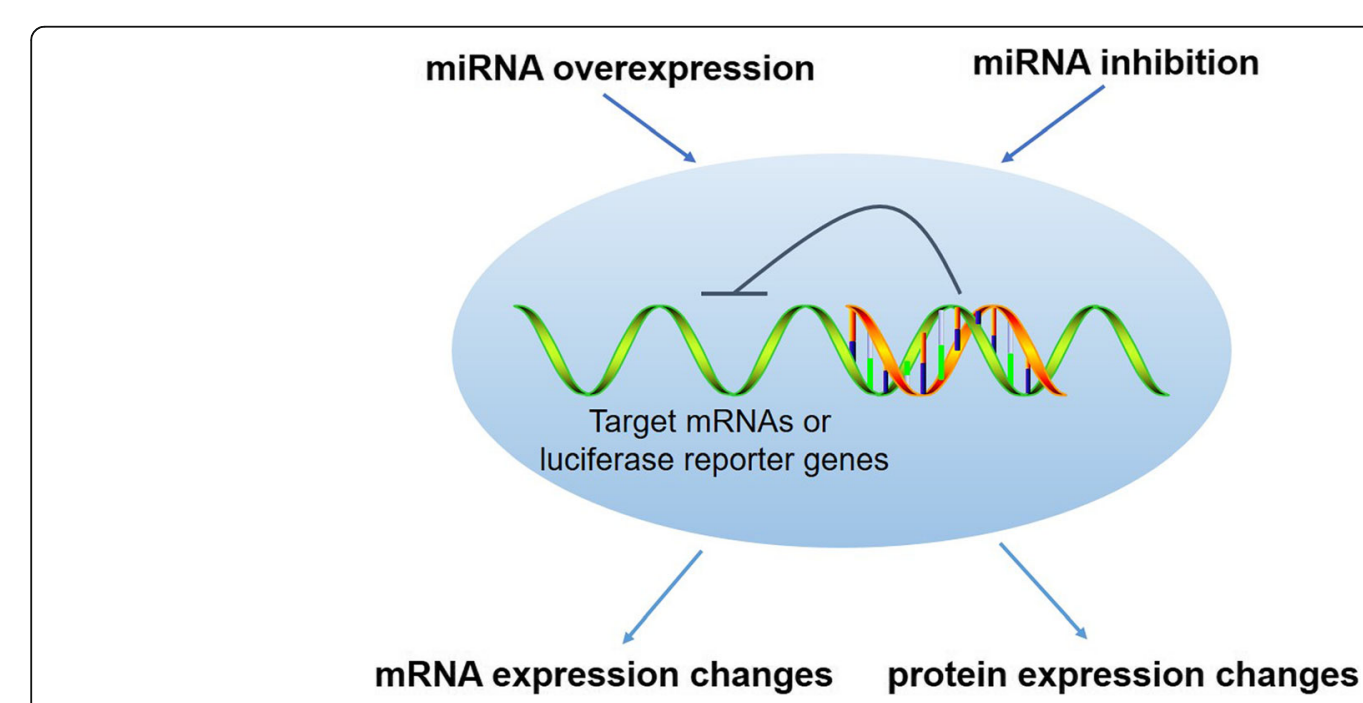

Fig. 2 Schematic illustration on the experimental strategies based on gene expression profiling for miRNA target identification 
MiRNA targets could then be indirectly indicated through measuring luciferase signals. Using this strategy, Mangone et al. engineered 275 luciferase reporter genes with human 3'-UTRs and two cancer relevant miRNAs, let-7c and miR-10b, were chosen to screen possible targets [25]. A large number of novel genes were then identified for these miRNAs, among which only $32 \%$ of them were consistent with bioinformatic predictions. Similarly, 139 luciferase reporter genes with predicted human 3'-UTRs were also constructed by Penalva et al. for screening possible targets for liver-specific miR-122, showing the prediction accuracy was $\sim 37 \%$ [26]. This method is sensitive and can identify direct targets for miRNAs, but it is limited by the high costs, shortage of 3'-UTR libraries and low throughput.

To realize high-throughput identification, indirect strategies based on quantification of global gene expression changes following miRNA overexpression or inhibition were developed (Fig. 2). After collection of possible targets through detecting gene expression changes, miRNA-mRNA interactions could be further indicated by bioinformatics. For instance, Johnson et al. overexpressed brain-specific miR-124 or muscle-specific miR-1in HeLa cells and analyzed the gene expression profiles through microarray, showing down-regulation of genes with special expression patterns in brain or muscle and the 3'-UTRs of these mRNAs tended to pair to the 5 '-end of miRNAs [27]. Similarly, expression of mRNAs was profiled by microarray analysis after overexpression or inhibition of cartilage-specific miR-140 in murine C3H10T1/2 fibroblast cells, resulted in 49 genes were simultaneously detected in mRNA samples from cells overexpressed or repressed with miR-140 [28]. With technique stable isotope labeling by amino acids in cell culture (SILAC), protein expression changes post modulation in miRNA expression could be read out. SILAC was then used to indicate targets for several miRNAs through overexpressing them in different cells, showing hundreds of proteins were modulated by these miRNAs $[29,30]$. Additionally, through measuring mRNA translation rates with ribosome profiling, Bartel et al. compared intracellular protein levels and mRNA levels after overexpression of miRNA in HeLa cells and showed mammalian miRNAs regulate gene expression mainly through mRNA degradation [31]. These methods are quantitative and high throughput, while it is unable to distinguish the direct or indirect targets of miRNAs, since primary and secondary targets are both yielded. Meanwhile, these methods cannot provide detailed information about miRNA-mRNA interactions. Additional bioinformatic methods are thereby always needed for further analysis.

\section{Immunoprecipitation}

Since miRNAs regulate their targets in RISC, it is therefore possible to rule out indirect targets through isolation of RISC and bound mRNAs. Strategies that rely on the immunoprecipitation (IP) of RISC proteins using specific antibody to isolate and identify bound mRNAs in RISC were then proposed (Fig. 3). After obtaining data sets through high-throughput analysis of isolated mRNAs in RISC, targets for miRNAs could be further indicated through bioinformatics. For example, Hannon et al. used AGO2 antibody to capture RISC and isolated bound mRNAs for further analysis with microarray, followed by identifying targets for miR-124 [32]. Similarly, target genes in RISC were isolated with AGO antibody and further analyzed by RNA-seq for identifying targets for miR-375 and miR-155 [33, 34]. Using antibodies targeting GW182 family proteins AIN-1 and AIN-2, Han et al. isolated and identified miRNA targets in RISC of C. elegans [35]. While, low efficiency resulted

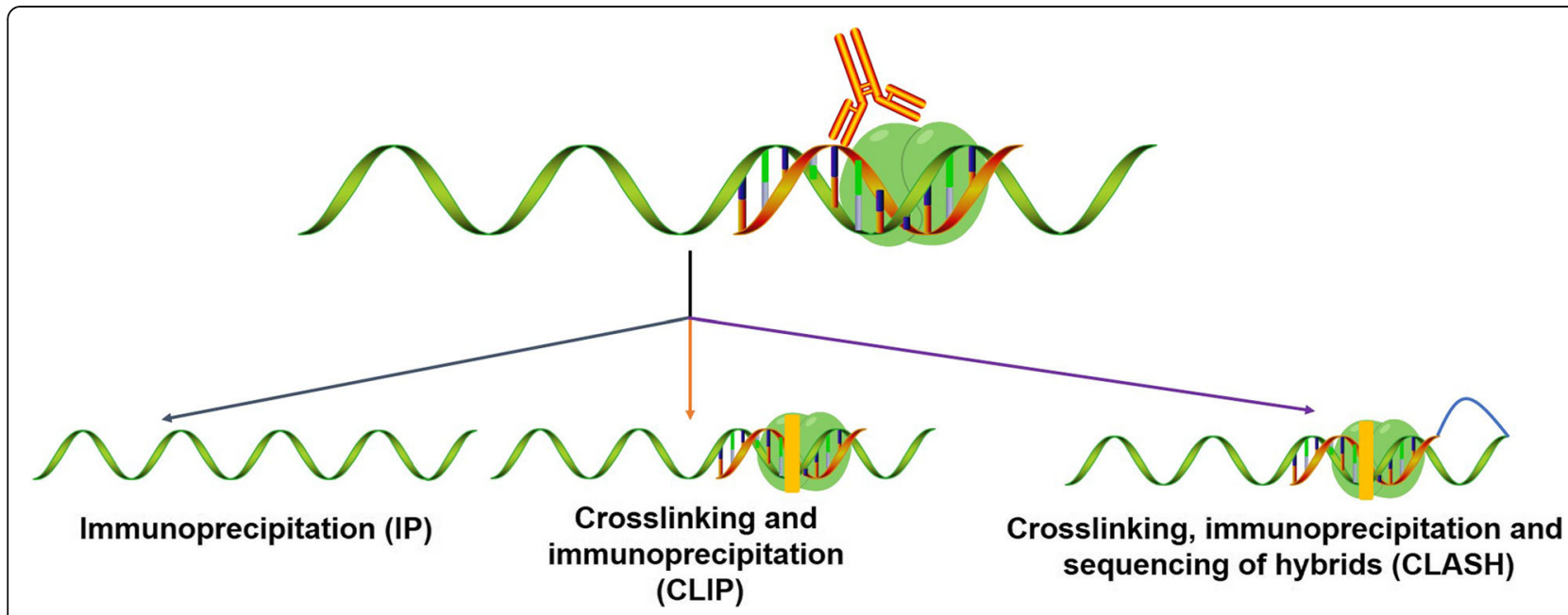

Fig. 3 Schematic illustration on the immunoprecipitation-based strategies for miRNA target identification 
from possible dissociation between mRNAs and RISC proteins during immunoprecipitation require further refinements of this method.

Provided that some nucleic acids and amino acids are photo-sensitive and could be crosslinked upon $254 \mathrm{~nm}$ irradiation, capture efficiency could thus be improved through photo-crosslinking of AGO with bound RNAs. Crosslinking and immunoprecipitation (CLIP) method that uses ultraviolet (UV) light to covalently conjugate protein-RNA was then developed (Fig. 3). After immunoprecipitation with a specific AGO antibody, miRNAs, their targets and AGO protein are precipitated together for further sequencing analysis. For example, Darnell et al. used CLIP to map interaction networks for miR-124, which simultaneously generated AGO-miRNA and AGO-mRNA data sets through high-throughput sequencing [36]. To further increase the capture efficiency, Tuschl et al. developed photoactivatable ribonucleoside-enhanced CLIP (PAR-CLIP) method, which incorporated photo-reactive 4-thiouridine into RNAs to more efficiently crosslink to nearby biomolecules upon UV irradiation [37]. While, due to the indirect isolation and identification, additional bioinformatic analysis are still needed to reveal miRNA-mRNA interactions from the CLIP data [38, 39]. To address this issue, crosslinking, immunoprecipitation and sequencing of hybrids (CLASH) method, which is similar to CLIP but ligates miRNA and target mRNA in RISC together for further sequencing analysis, was developed (Fig. 3). Using this method, Tollervey et al. obtained data sets of many miRNA-mRNA conjugates and revealed frequent non-canonical bindings for human miRNAs [19, 40]. Even though CLASH could reveal direct interaction between miRNA and target mRNAs, the efficiency of this method is relatively low. Moreover, immunoprecipitation strategies are not miRNA specific. Further improvements of these immunoprecipitation methods are still highly demanded before they can be used to map global miRNA-mRNA networks.

\section{Pull-down}

To improve the capture efficiency and specificity of target identification toward given miRNA, chemical tags labeled miRNA mimics were constructed and applied to capture miRNA associated targets inside cells through pull-down method. Initially, 3'-biotinylated miRNAs were used to capture miRNA targets through enrichment of miRNAs and their associated target mRNAs on streptavidin beads (Fig. 4), which were subject to further analysis to reveal miRNA-mRNA interactions. For instance, by using 3'-biotinylated miR-10a, Lund et al. identified mRNAs that interacted with miR-10a through microarray analysis and revealed miR-10a could enhance ribosome mRNA translation through binding with the 5'-UTR [41]. Similarly, Lieberman et al. used 3'-biotinylated miR-34a to identify their targets in cancer cells in combination with microarray analysis [42]. To further improve the capture efficiency, photo-reactive molecules could be conjugated to labeled miRNAs for covalently binding to target mRNAs upon light irradiation. To this end, miRNA target RNA affinity purification (miR-TRAP) strategy was developed by Rana et al. and several target mRNAs for miR-29a and miR-135b were identified [43].

In addition to strategies based on using biotinyated miRNAs as probes, Tsai et al. developed an alternative strategy, which used digoxigenin (DIG)-labeled pre-miRNA as probe and was termed as labeled miRNA pull-down (LAMP) assay system [44]. The DIG-labeled pre-miRNA probe was incubated with cell extracts, leading to generation of DIG-labeled mature miRNA probe upon cleavage by Dicer and further binding of the probe with target genes. Through immunoprecipitation by anti-DIG antiserum, DIG-labeled miRNA and bound mRNA complex were obtained for further analysis. With this strategy, they found a novel target gene hand2 for zebrafish miR-1. While, the effect of DIG on miRNA function and the possibility of introduction of DIG-labeled miRNA probes into living cells for miRNA target identification remain unknown.

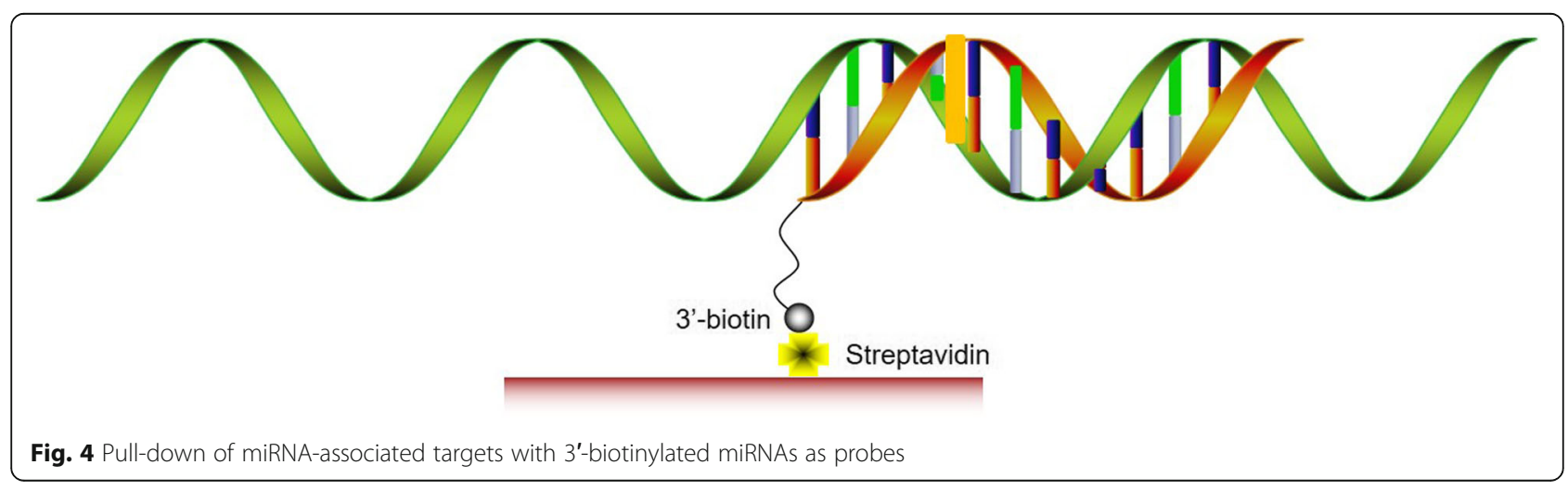


Even though 3'-bitonylation methods hold great promise due to the high efficiency and miRNA specificity, recent evidences raise another concern on the suitability of them for miRNA target identification, since 3'-biotinylation greatly hindered the incorporation of miRNA into RISC $[22,45]$. The loss of miRNA function suggests 3'-biotynlated miRNAs are not ideal probes for miRNA target identification. To avoid 3'-biotinylation, Hall et al. then screened biotinylation sites on miRNAs to make sure the chemical modification did not affect miRNA function and combined this method with CLIP (Fig. 5) [22]. The resulted miRNA crosslinking and immunoprecipitation (miR-CLIP) method used miR-106a mimic probe with biotin modification and photo-reactive molecule modification at middle sites. The resulted probe cross-linked to target mRNAs in RISC upon light irradiation, followed by immunoprecipitation of RISC with AGO2 antibody and further enrichment of miRNA-associated targets on streptavidin beads. Deep sequencing of the isolated targets then reveled a special interaction between miR-106a and long noncoding RNA H19. This method greatly improved the identification accuracy through excluding the side effect of biotin on miRNA function. Nevertheless, it is not universal and could not be easily adopted for other miRNAs, since biotinylated sites should be screened prior to target identification. Moreover, combination of immunoprecipitation method also led to low capture efficiency.

In recent years, bio-orthogonal chemistry has been developed as a biocompatible ligation strategy for post-labeling of biomolecules in vitro and in vivo [46]. The small bio-orthogonal group could be first loaded onto biomolecules without affecting their biological function and different tags containing complementary bio-orthogonal groups could be further conjugated to these biomolecules through corresponding bio-orthogonal chemistry. To establish a universal strategy for tagging miRNAs without affecting their intracellular function and efficient capture of miRNA-associated targets, we recently developed a novel strategy for miRNA target identification based on photo-click chemistry (Fig. 6) [47]. In comparison with 3'-biotinylated miRNAs, photo-clickable miRNA with tetrazole modification at the 3 '-end of several miRNAs showed intact biological function inside cells, which were also comparable to unmodified miRNA mimics. The presence of tetrazole on miRNAs and their associated target genes then allowed further attachment of biotin to these complexes through photo-click reaction [48], which could be enriched and isolated with streptavidin beads for further analysis. Through using photo-clickable miR-122 as probes, novel miR-122 targets and miR-122-involved cellular regulatory pathway were successfully revealed. In light of the excellent compatibility of tetrazole modification on miRNA function, this method holds great potential as a universal strategy for miRNA target identification. While, possible dissociation between photo-clickable miRNA and target mRNAs may exist during pull-down. In combination with crosslinking method that can covalently conjugate miRNA and target mRNAs together may further improve the efficiency, which are now underway in our group.

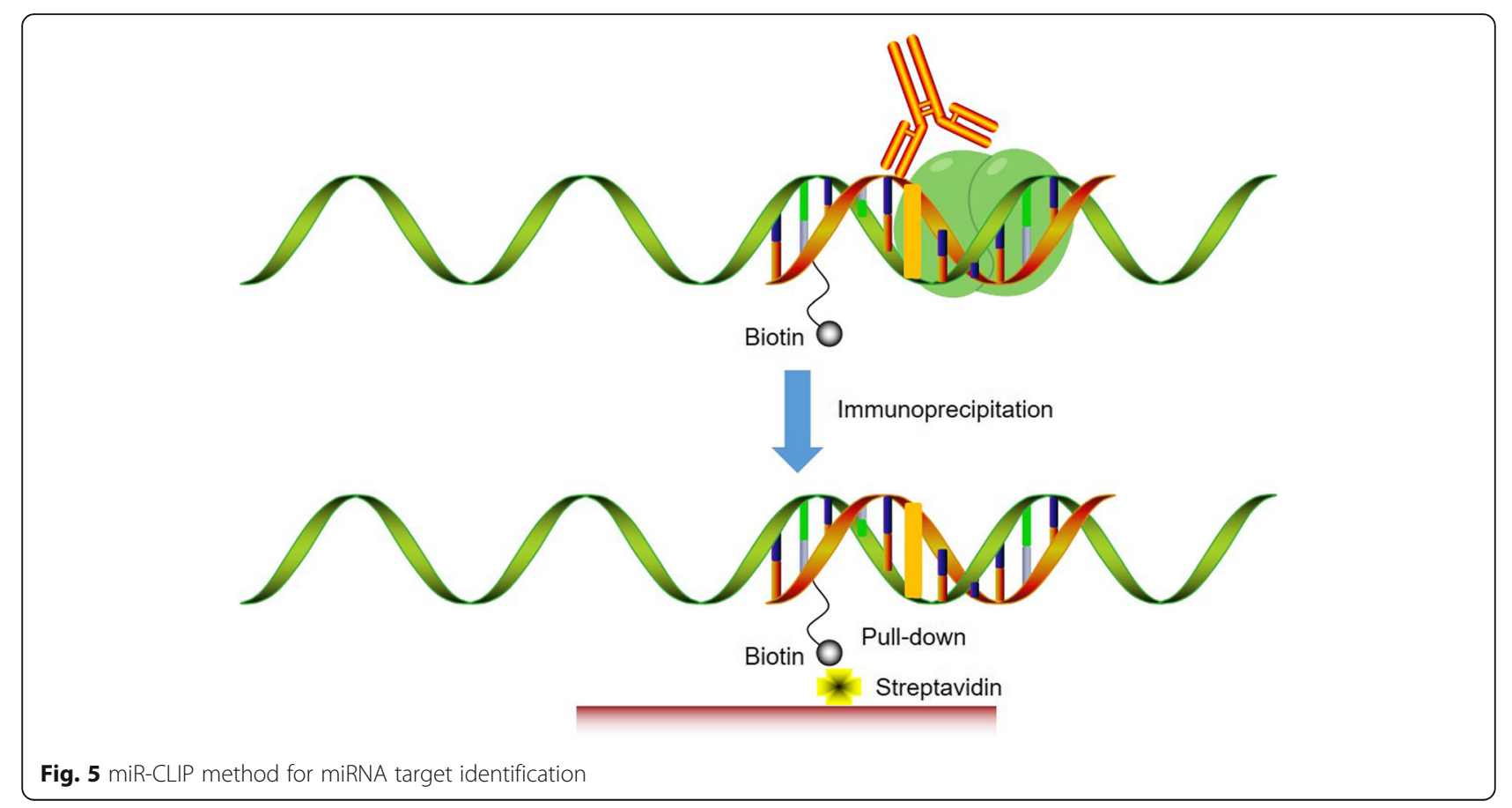




\section{Photo-clickable microRNA
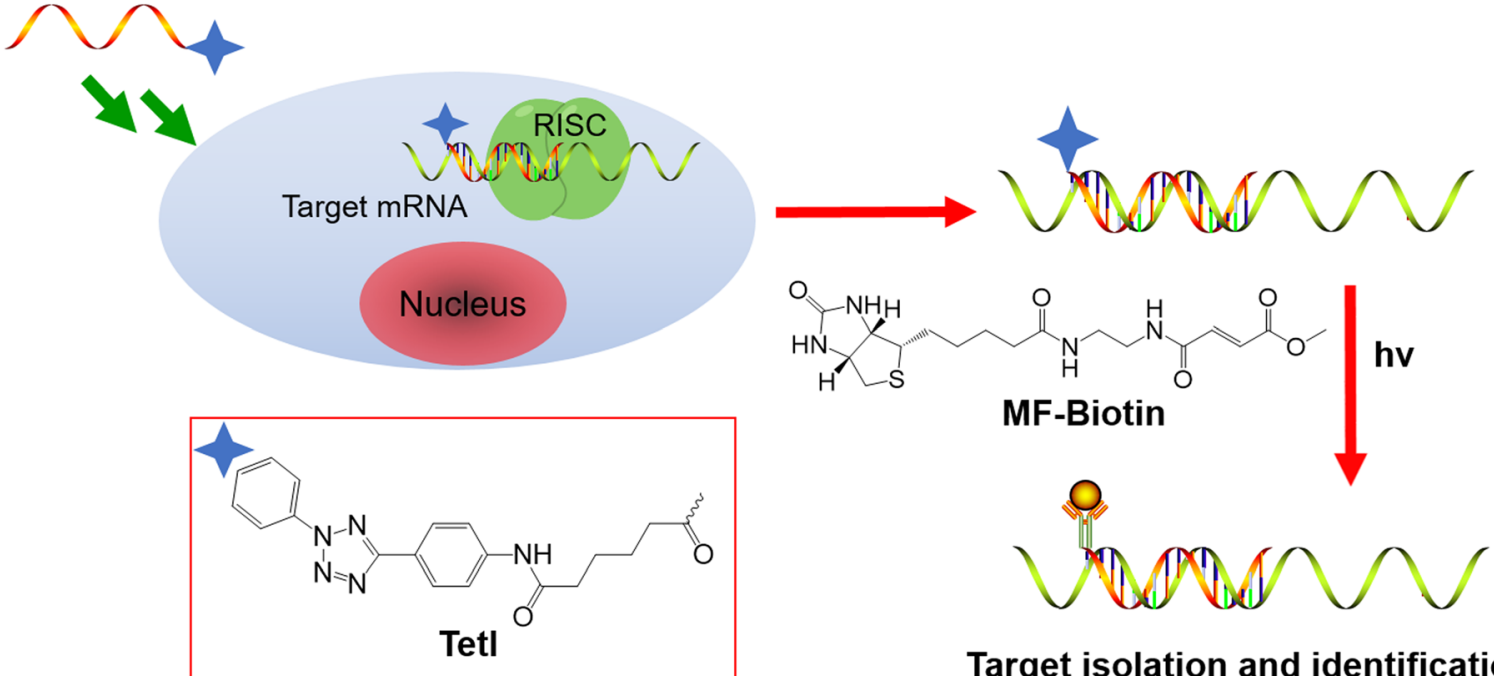 \\ Target isolation and identification}

Fig. 6 Photo-clickable miRNA for miRNA target identification. Adapted from reference [47] with permission

\section{Conclusion and perspective}

In this review paper, we summarize and compare current experimental strategies for intracellular target identification of miRNAs. Each strategy has its inherent advantages and limitations, which require further refinements of these methods before proceeding to globally mapping miRNA regulatory networks. Accuracy and efficiency are the two major factors that need to be considered during development and improvement of experimental strategies. In comparison with gene expression profiling methods, accuracy of immunoprecipitation methods is greatly improved, since false-positive target genes outside RISC are excluded. However, relying on specific antibody to isolate target genes further decreases the efficiency of target isolation and identification. Meanwhile, due to the indirect isolation and identification, bioinformatics are always needed to reveal miRNA-mRNA interactions. Currently the most promising strategy is the pull-down method, since it uses tagged miRNAs as probes to directly isolate miRNA-associated targets. The biocompatibility of chemical tags toward miRNA modification is then critical for miRNA target identification. Recent results revealed 3'-biotinylation greatly hampered the association of miRNA with their targets in RISC $[22,45]$, indicating direct biotinylation is not suitable for miRNA target identification. To address this issue, we recently developed photo-clickable miRNA that pre-tagged miRNA with tetrazole groups on 3'-miRNAs without affecting their function, which allowed further attachment of affinity tags onto miRNA-mRNA complexes post their binding [47]. Moreover, combination of other bio-orthogonal reactions, such as click reaction and tetrazine reaction [46], should further improve the accuracy and efficiency of miRNA target identification through miRNA probes bearing bio-orthogonal groups and should allow simultaneous target identification for different miRNAs in same biological environment. With the development and improvement of experimental strategies for miRNA target identification, a clear picture of miRNA regulatory networks inside cells will be drawn in the future, which will ultimately lead to huge progresses in therapeutic treatments with miRNAs as targets.

\section{Abbreviations}

3'-UTR: 3'-untranslated region; AGO: Argonaute; CLASH: Crosslinking, immunoprecipitation and sequencing of hybrids; CLIP: Crosslinking and immunoprecipitation; IP: Immunoprecipitation; miR-CLIP: miRNA crosslinking and immunoprecipitation; miRNA: microRNA; miR-TRAP: miRNA target RNA affinity purification; RISC: RNA-induced silencing complex; SILAC: Stable isotope labeling by amino acids in cell culture

Acknowledgements

Not applicable.

Funding

National Natural Science Foundation of China $(21877058,21672103$, 21572102, 21372115).

Availability of data and materials

Not applicable.

Authors' contributions

\lrcorner $L$ and $Y Z$ wrote and revised the manuscript. Both authors read and approved the final manuscript.

Ethics approval and consent to participate Not applicable.

Consent for publication

Not applicable.

Competing interests

The authors declare that they have no competing financial interest. 


\section{Publisher's Note}

Springer Nature remains neutral with regard to jurisdictional claims in published maps and institutional affiliations.

Received: 31 March 2017 Accepted: 27 December 2018 Published online: 14 February 2019

\section{References}

1. Bartel DP. MicroRNAs: target recognition and regulatory functions. Cell. 2009;136(2):215-33.

2. Wightman $\mathrm{B}, \mathrm{Ha} \mathrm{I}$, Ruvkun G. Posttranscriptional regulation of the heterochronic gene lin-14 by lin-4 mediates temporal pattern formation in C. elegans. Cell. 1993;75(5):855-62.

3. Lee RC, Feinbaum RL, Ambros V. The C. elegans heterochronic gene lin-4 encodes small RNAs with antisense complementarity to lin-14. Cell. 1993; 75(5):843-54.

4. Pasquinelli AE, Reinhart BJ, Slack F, Martindale MQ, Kuroda MI, Maller B, et al. Conservation of the sequence and temporal expression of let-7 heterochronic regulatory RNA. Nature. 2000;408(6808):86-9.

5. Reinhart BJ, Slack FJ, Basson M, Pasquinelli AE, Bettinger JC, Rougvie AE, et al. The 21-nucleotide let-7 RNA regulates developmental timing in Caenorhabditis elegans. Nature. 2000;403(6772):901-6.

6. miRBase: http://www.mirbase.org/.

7. Lewis BP, Burge CB, Bartel DP. Conserved seed pairing, often flanked by adenosines, indicates that thousands of human genes are microRNA targets. Cell. 2005:120(1):15-20.

8. Carrington JC, Ambros V. Role of microRNAs in plant and animal development. Science. 2003;301(5631):336-8.

9. Esquela-Kerscher A, Slack FJ. Oncomirs - microRNAs with a role in cancer. Nat Rev Cancer. 2006;6(4):259-69.

10. Rupaimoole R, Slack FJ. MicroRNA therapeutics: towards a new era for the management of cancer and other diseases. Nat Rev Drug Discov. 2017;16(3): 203-22.

11. Li J, Tan S, Kooger R, Zhang C, Zhang Y. MicroRNAs as novel biological targets for detection and regulation. Chem Soc Rev. 2014;43(2):506-17.

12. Hausser J, Zavolan M. Identification and consequences of miRNA-target interactions--beyond repression of gene expression. Nat Rev Genet. 2014; 15(9):599-612

13. Bracken CP, Scott HS, Goodall GJ. A network-biology perspective of microRNA function and dysfunction in cancer. Nat Rev Genet. 2016;17(12): 719-32.

14. He L, Hannon GJ. MicroRNAs: small RNAs with a big role in gene regulation. Nat Rev Genet. 2004;5(7):522-31.

15. Singh NK. miRNAs target databases: developmental methods and target identification techniques with functional annotations. Cell Mol Life Sci. 2017; 74(12):2239-61.

16. Stanhope Stephen A, Sengupta S, den Boon J, Ahlquist P, Newton Michae A. Statistical use of argonaute expression and RISC assembly in microRNA target identification. PLoS Comput Biol. 2009;5(9):e1000516.

17. Tarang S, Weston MD. Macros in microRNA target identification: a comparative analysis of in silico, in vitro and in vivo approaches to microRNA target identification. RNA Biol. 2014;11(4):324-33.

18. Pinzon N, Li B, Martinez L, Sergeeva A, Presumey J, Apparailly F, et al. microRNA target prediction programs predict many false positives. Genome Res. 2017;27(2):234-45

19. Helwak A, Kudla G, Dudnakova T, Tollervey D. Mapping the human miRNA interactome by CLASH reveals frequent noncanonical binding. Cell. 2013; 153(3):654-65.

20. Khorshid M, Hausser J, Zavolan M, van Nimwegen E. A biophysical miRNAmRNA interaction model infers canonical and noncanonical targets. Nat Methods. 2013;10(3):253-5.

21. Seok H, Ham J, Jang ES, Chi SW. MicroRNA target recognition: insights from transcriptome-wide non-canonical interactions. Mol Cells. 2016:39(5):375-81.

22. Imig J, Brunschweiger A, Brummer A, Guennewig B, Mittal N, Kishore S, et al. miR-CLIP capture of a miRNA targetome uncovers a lincRNA H19-miR106a interaction. Nat Chem Biol. 2015;11(2):107-14

23. Martinez-Sanchez A, Murphy CL. MicroRNA target identification experimental approaches. Biology. 2013;2(1):189-205.

24. Oerom UA, Lund AH. Experimental identification of microRNA targets. Gene. 2010;451(1-2):1-5
25. Wolter JM, Kotagama K, Pierre-Bez AC, Firago M, Mangone M. 3'LIFE: a functional assay to detect miRNA targets in high-throughput. Nucleic Acids Res. 2014;42(17):e132.

26. Boutz DR, Collins PJ, Suresh U, Lu M, Ramirez CM, Fernandez-Hernando C, et al. Two-tiered approach identifies a network of cancer and liver diseaserelated genes regulated by miR-122. J Biol Chem. 2011;286(20):18066-78.

27. Lim LP, Lau NC, Garrett-Engele P, Grimson A, Schelter JM, Castle J, et al. Microarray analysis shows that some microRNAs downregulate large numbers of target mRNAs. Nature. 2005;433(7027):769-73.

28. Nicolas FE, Pais H, Schwach F, Lindow M, Kauppinen S, Moulton V, et al. Experimental identification of microRNA-140 targets by silencing and overexpressing miR-140. RNA. 2008;14(12):2513-20.

29. Baek D, Villen J, Shin C, Camargo FD, Gygi SP, Bartel DP. The impact of microRNAs on protein output. Nature. 2008;455(7209):64-71.

30. Selbach M, Schwanhausser B, Thierfelder N, Fang Z, Khanin R, Rajewsky N. Widespread changes in protein synthesis induced by microRNAs. Nature. 2008;455(7209):58-63.

31. Guo H, Ingolia NT, Weissman JS, Bartel DP. Mammalian microRNAs predominantly act to decrease target mRNA levels. Nature. 2010;466(7308): 835-40.

32. Karginov FV, Conaco C, Xuan Z, Schmidt BH, Parker JS, Mandel G, et al. A biochemical approach to identifying microRNA targets. Proc Natl Acad Sci U S A. 2007;104(49):19291-6.

33. Pickl JM, Tichy D, Kuryshev $\mathrm{V}$, Tolstov $Y$, Falkenstein $M$, Schuler J, et al. Ago-RIP-Seq identifies Polycomb repressive complex I member CBX7 as a major target of miR-375 in prostate cancer progression. Oncotarget. 2016; 7(37):59589-603

34. Meier J, Hovestadt V, Zapatka M, Pscherer A, Lichter P, Seiffert M. Genomewide identification of translationally inhibited and degraded miR-155 targets using RNA-interacting protein-IP. RNA Biol. 2013;10(6):1018-29.

35. Zhang L, Ding L, Cheung TH, Dong MQ, Chen J, Sewell AK, et al. Systematic identification of $C$. elegans miRISC proteins, miRNAs, and mRNA targets by their interactions with GW182 proteins AIN-1 and AIN-2. Mol Cell. 2007; 28(4):598-613.

36. Chi SW, Zang JB, Mele A, Darnell RB. Argonaute HITS-CLIP decodes microRNA-mRNA interaction maps. Nature. 2009;460(7254):479-86.

37. Hafner $M$, Landthaler $M$, Burger $L$, Khorshid $M$, Hausser J, Berninger $P$, et al. Transcriptome-wide identification of RNA-binding protein and microRNA target sites by PAR-CLIP. Cell. 2010;141(1):129-41.

38. Wang $T$, Xiao G, Chu Y, Zhang MQ, Corey DR, Xie Y. Design and bioinformatics analysis of genome-wide CLIP experiments. Nucleic Acids Res. 2015:43(11):5263-74.

39. Uhl M, Houwaart T, Corrado G, Wright PR, Backofen R. Computational analysis of CLIP-seq data. Methods. 2017:118-119:60-72.

40. Helwak A, Tollervey D. Mapping the miRNA interactome by cross-linking ligation and sequencing of hybrids (CLASH). Nat Protoc. 2014:9(3):711-28.

41. Orom UA, Nielsen FC, Lund AH. MicroRNA-10a binds the 5'UTR of ribosomal protein mRNAs and enhances their translation. Mol Cell. 2008:30(4):460-71.

42. Lal A, Thomas MP, Altschuler G, Navarro F, O'Day E, Li XL, et al. Capture of microRNA-bound mRNAs identifies the tumor suppressor miR-34a as a regulator of growth factor signaling. PLoS Genet. 2011;7(11):e1002363.

43. Baigude $H$, Ahsanullah LZ, Zhou Y, Rana TM. miR-TRAP: a benchtop chemical biology strategy to identify microRNA targets. Angew Chem Int Ed. 2012;51(24):5880-3.

44. Hsu RJ, Yang HJ, Tsai HJ. Labeled microRNA pull-down assay system: an experimental approach for high-throughput identification of microRNAtarget mRNAs. Nucleic Acids Res. 2009;37(10):e77.

45. Guo YE, Steitz JA. 3'-biotin-tagged microRNA-27 does not associate with Argonaute proteins in cells. RNA. 2014;20(7):985-8.

46. Sletten EM, Bertozzi CR. Bioorthogonal chemistry: fishing for selectivity in a sea of functionality. Angew Chem Int Ed. 2009:48(38):6974-98.

47. Li J, Huang L, Xiao X, Chen Y, Wang X, Zhou Z, et al. Photoclickable MicroRNA for the intracellular target identification of MicroRNAs. J Am Chem Soc. 2016:138(49):15943-9.

48. Lim RK, Lin Q. Photoinducible bioorthogonal chemistry: a spatiotemporally controllable tool to visualize and perturb proteins in live cells. Acc Chem Res. 2011;44(9):828-39. 